\title{
Third party disability for significant others of individuals with tinnitus: A cross-sectional survey design
}

\author{
Eldre Beukes ${ }^{1}$, Gerhard Andersson ${ }^{2}$, and Vinaya Manchaiah ${ }^{3}$ \\ ${ }^{1}$ Anglia Ruskin University - Cambridge Campus \\ ${ }^{2}$ Linkopings universitet \\ ${ }^{3}$ Lamar University
}

August 31, 2021

\begin{abstract}
Background: The impact of tinnitus on significant others (SOs) is largely unknown. Objectives: The study aims included investigating third-party disability in a sample of SOs of individuals with tinnitus and to investigate factors associated with third-party disability. Design: The study used a cross-sectional survey design. Setting: The study was undertaken online Participants: Individuals with tinnitus together with their SOs completed questionnaires online. Outcome measures: The SO sample completed the newly developed Consequences of Tinnitus on Significant Others Questionnaire (CTSOQ). Individuals with tinnitus completed standardized self-reported outcome measures for tinnitus severity, anxiety, depression, insomnia, hearing related quality of life, tinnitus cognitions, hearing disability and hyperacusis to identify any associations between these scores and those of the significant others. Results: A total of 194 pairs of individuals with tinnitus and their SOs that participated, with a mean age of 57 and 56 years, respectively. The CTSOQ showed that 37 (19\%) of SOs had mild impact, 58 (29\%) had significant impact, and $101(52 \%)$ had severe impact. The clinical variables of tinnitus severity, anxiety and hyperacusis in individuals with tinnitus were the best predictors of the impact of tinnitus on SOs. Conclusions: This study indicates that SOs of individuals with tinnitus may experience third-party disability. The effect of the individual's tinnitus on SOs may be greater when the individual with tinnitus has greater tinnitus severity, anxiety and hyperacusis. Ways of mitigating these effects should be prioritized such as involving them in the tinnitus management process.
\end{abstract}

\section{Hosted file}

Main_document_noauthors_26July21.docx available at https://authorea.com/users/432394/ articles/535884-third-party-disability-for-significant-others-of-individuals-withtinnitus-a-cross-sectional-survey-design 


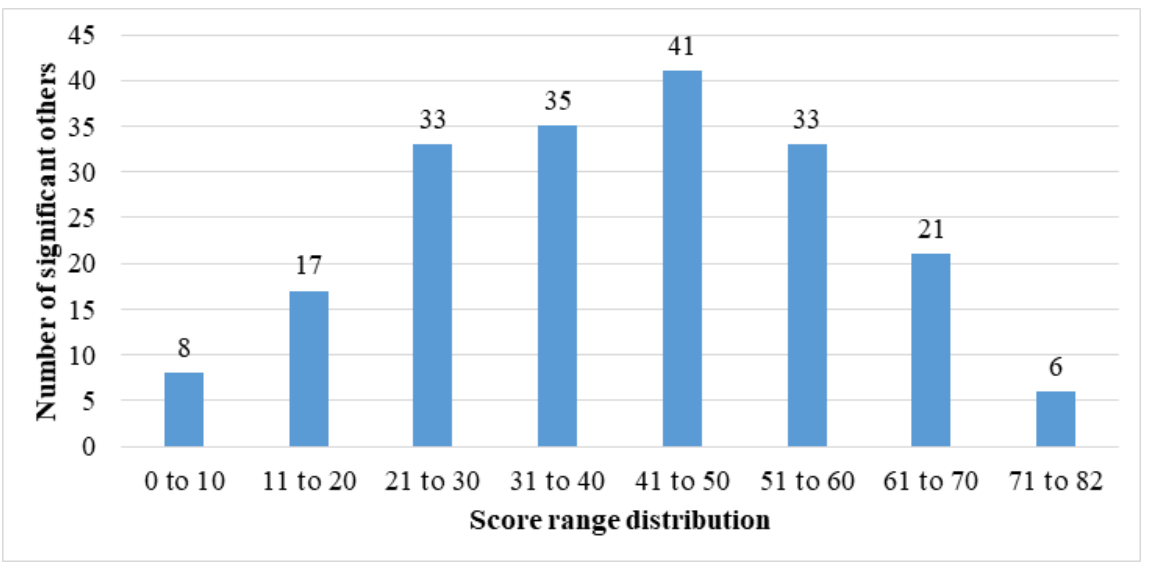

\section{Hosted file}

Table 1.docx available at https://authorea.com/users/432394/articles/535884-third-partydisability-for-significant-others-of-individuals-with-tinnitus-a-cross-sectional-surveydesign

\section{Hosted file}

Table 2.docx available at https://authorea.com/users/432394/articles/535884-third-partydisability-for-significant-others-of-individuals-with-tinnitus-a-cross-sectional-surveydesign

\section{Hosted file}

Table 3.docx available at https://authorea.com/users/432394/articles/535884-third-partydisability-for-significant-others-of-individuals-with-tinnitus-a-cross-sectional-surveydesign 